\title{
Growth Differentiation Factor 11 Measurement
}

National Cancer Institute

\section{Source}

National Cancer Institute. Growth Differentiation Factor 11 Measurement. NCI

Thesaurus. Code C135422.

The determination of the amount of growth differentiation factor 11 in a biological sample. 